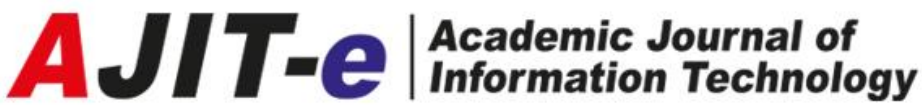

\section{General Policies}

1. Bilişim Teknolojileri Online Dergisi, uses the name Online Academic Journal of Information Technology in English and AJIT-e is the short name. In the following sections, the acronym AJIT-e, which replaces the name of Bilişim Teknolojileri Online Dergisi, will be used.

2. AJIT-e, which began its publishing life as an online electronic journal in September 2010, is international peer-reviewed journal. AJIT-e publishes numbers four times a year: Winter - Spring, Summer and Fall.

3. AJIT-e is published only electronically. In AJIT-e, published at http://dergipark.org.tr/ajit-e, the whole process is carried out through Dergipark.

4. AJIT-e is committed to applying publication ethics to the highest standards and following the application guide prepared by Committee on Publication Ethics (COPE).

5. Articles in AJIT-e are archived with LOCKSS (Lots of Copies Keep Stuff Safe) system.

6. AJIT-e supports and accepts the Budapest Open Access Initiative. In this context, AJIT-e open Access policy follows and is licensed with Creative Commons Attribution-Same License Share 4.0 International License. Access to published studies is free and all published articles are shared with the world of science at national and international level. Application have been made to international indexes and are currently indexed in widely known index and content browsing services such as TRDizin, Index Copernicus, Crossref, Google Scholar, EBSCO, ProQuest.

7. AJIT-e has also registered with DOI since July 2011 and assigns DOI number for each article accepted to publication.

8. The author may request the "Publication Acceptance Document" signed by the editor for the article accepted for publication.

9. AJIT-e does not accept the article for any number. Articles can always be sent to the journal. The articles whose review process is completed are selected by the editor for the number approved. 
10. All legal and scientific responsibility for the content of the articles published in AJIT-e belongs to the author (s).

11. All authors who submit articles to AJIT-e have equal rights. No privileges are given to the author during the review, acceptance, and publishing processes of the articles. The order in which accepted articles are published is set up depending on the time of acceptance. However, the editorial board reserves the right to make changes where it deems necessary.

12. AJIT-e is published within the Akademik Bilişim Araştırmaları Derneği (ABA). (English name is Society of Academic Research on Informatics)

13. Since 2010, the year it was founded in AJIT-e, the journal secretariat, editors and referees voluntarily carry out the whole process. However, the server and domain costs, Crossref membership fees and article registration fees received by Crossref on each DOI record, and many more costs, require the support of authors. For this reason, Society of Academic Research on Informatics has been established to continue the existence of our journal, which has been published for more than 10 years. Students and young academics are supported, and scientific activities are organized by the association, especially the publication of the journal. In this context, 500 Turkish Lira Article Processing Charge (APC) was decided from articles. The editorial board of the journal is waiting for your support in this regard. Detailed information can be found on this page.

14. APC has no positive or negative effect on the review process. Our policy in article 11 will always apply.

15. AJIT-e uses information such as name, title and e-mail addresses shared on the website only for the stated purposes of this journal; it does not use it for any other purpose or make it available to others.

16. The "Copyright Transfer Form" must be filled out and signed by all authors and uploaded to the journal system.

17. All rights of the published article are published as belonging to AJIT-e. 
18. As new communication environments are much more advantageous than print media in terms of speed and broadcast processes, the future of academic publishing has begun to take shape around new communication environments such as the Internet. Articles can be published long before the printed versions of journals. AJIT-e started publication in 2010 to provide a resource and publication environment for research interested in the field of communication and informatics.

\section{Scope of AJIT-e}

19. AJIT-e is a multidisciplinary journal that covers research and studies examined according to scientific criteria within the framework of communication sciences and informatics technologies. AJIT-e publication areas include the following topics:

MEDIA AND COMMUNICATION SCIENCES

COMPUTER FORENSICS

DOCUMENT AND RECORDS MANAGEMENT

KNOWLEDGE MANAGEMENT

LEGAL INFORMATICS

DISTRIBUTED INFORMATICS SYSTEMS

E-CRM

E-GOVERNANCE

E-MARKETING

E-SCM

E-GOVERNANCE

HOSPITAL INFORMATION SYSTEMS

INNSOURCING/OUTSOURCING

ENTERPRISE RESOURCE PLANNING

RADIOLOGY INFORMATION SYSTEMS

DIGITAL RIGHTS MANAGEMENT
HEALTH TECHNOLOGIES

MULTIMEDIA

KNOWLEDGE SECURITY

INFORMATICS ETHICS

INFORMATICS THEORY

E-LEARNING

E-TRANSFORMATION

E-ORGANIZATION

E-ADVERTISING

E-PUBLISHING AND E- PUBLICATION

E-BUSINESS / E-COMMERCE

INNOVATION

DECISION SUPPORT SYSTEMS

PROJECT MANAGEMENT

DIGITAL ENTERTAINMENT AND

GAMES

DIGITAL COMMUNICATION

ENVIRONMENTS/MEDIA 
DIGITAL COMMUNICATION SYSTEMS

HEALTH INFORMATION STRATEGIES

SOCIAL NETWORKS

TELECOMMUNICATION

DATA WAREHOUSES / DATA ISLETS

DATA MINING

ARTIFICIAL INTELLIGENCE

NEW MEDIA / COMMUNICATION

ENVIRONMENTS

BUSINESS MIND
HEALTH INFORMATION STRATEGIES

SYSTEM ANALYSIS AND DESIGN

SUPPLY CHAIN MANAGEMENT

MEDICAL INFORMATICS

DATA SECURITY

DATABASE MANAGEMENT SYSTEMS

MANAGEMENT INFORMATION SYSTEMS

COMMUNICATION INFORMATICS

BUSINESS INFORMATICS

\section{The Qualification of Articles in AJIT-e}

20. Original articles based on scientific criteria and research that will contribute to the field are accepted by AJIT-e.

21. Review articles that have a detailed bibliography and reveal criticism and views on the subject under consideration are accepted by AJIT-e.

22. The studies obtained from the thesis or conference proceedings are published if they meet the following conditions.

- If the study was published as abstract; title of the article, name of the event, date and place information should be specified in the footnote.

- If the study was produced from postgraduate theses; The name of the thesis, the name of the consultant, the information of the university and institute and the date of completion of the thesis should be indicated in the footnote.

- If the study was supported by the research institution or fund; Name of the organization providing the support, project number and date of completion should be indicated in the footnote.

23. Submitted articles must not have been previously published in another journal or have not been accepted for publication.

24. Submitted articles should be uploaded in Word (doc, docx) format in order to create an review copy and to make layout work in case the publisher receives its approval. 


\section{Review Process}

25. Before the articles are sent to the referees, the following points are examined, and the articles found suitable for the review process are sent to the referees:

- The editorial board evaluates the scientific quality and originality and determines the area to which the work belongs, then evaluates the article's publication principles and its relevance to publication ethics.

- During the referee review process, the referees access the review copies added to the system and download the electronic copy of the article to their computers. In the downloaded copy, the word REVIEW COPY is clearly stated and does not include any statements regarding the author (s) of the study.

- Each referee evaluating the article evaluates according to the review criteria created in the system; In the referee review form, there is a field where they can report the necessary corrections and changes. Referees can write the details of the article or the corrections to be made here or they can also upload it to the system with an additional file. They also select the relevant item showing the result of the assessment.

- Double blind referee system is used in AJIT-e. The "positive" opinion of at least two referees is sought for the publication of the article. If one of the referees gives a "positive" opinion and the other a "negative" opinion, the article is sent to the third referee. After two "positive" referee opinions, the editorial board assigns numbers to the articles selected for publication. PDF copies are produced and added to the system.

- The relevant issue is published when the time comes then the article is made visible.

26. The review process is started for each article that satisfies the above conditions. The fee specified in article $\mathbf{1 3}$ is requested after the article has received approval from at least two referees. This fee has no positive or negative effect on the review process. As stated in Article 10, all authors have equal rights. 
27. According to the decisions taken by the relevant boards of TUBITAK ULAKBIM TRDizin, from the authors of the articles to be applied for publication in all journals in 2020 (except review article);

- Indicating and documenting the candidate article on the first-last page and in the method section of the candidate article (ethics committee name, decision date and number) for researches that require data collection by means of scale, questionnaire, interview, observation,

- Including information about the volunteer consent form being signed by the participant,

- Including these in the article as proof that ethical principles are taken into consideration during the data collection process (such as obtaining permission to use the information of others),

- It will be requested to indicate that the articles comply with research and publication ethics.

Your article will proceed to the referee review process after the necessary documents are uploaded.

28. When the "Correction" decision is taken for the submitted articles, the authors should make the necessary corrections within 15 days and upload the final version of the article to the system. Editorial board has the right to reject the article if the corrections are not made within the specified period.

29. In our journal, depending on the referee review, the article evaluation process is expected to take a maximum of 6 months for each article.

30. Author(s) considers criticism, suggestions and corrections of referees and the Editorial Board. They have the right to report their reasons if there are any issues they disagree with. The author (s) of the articles accepted or not accepted for publication are informed.

31. The author always has the right to withdraw his article. However, the articles assigned to the referee cannot be taken back by the author due to Dergipark's system. The review process must be completed before the author can withdraw his article. 
32. The plagiarism rate of the articles sent to our journal is determined by Turnitin. If the similarity rate determined before the referee appointment is over $20 \%$, the article is rejected before the referee evaluation process is started. Unpublishing is applied for plagiarism detected after publication and an editorial note is published in the journal for readers.

\section{Author Guidelines in AJIT-e}

\section{Writing Language}

33. Articles submitted to the journal are accepted in Turkish or English. The articles to be published must include Turkish and English abstracts and keywords determined by their authors.

\section{Writing Rules}

\section{Style of the Article}

34. Articles submitted to our journal must be fit for our template. Otherwise, the editorial board requests the author to make the necessary arrangements before appointing a referee. If the necessary regulation is not made within 15 days by the author of the editorial board stated in article 28 , he has the right to reject the article.

35. If the writing language of the article is Turkish, first, Turkish abstract and keywords must be included under the title of Turkish. Then, English abstracts and keywords must be included under the heading in English.

36. If the writing language of the article is English, first, English abstract and keywords must be included under the title of English. Then, Turkish abstracts and keywords must be included under the heading in Turkish.

37. The footnote condition specified in article 21 should be given under the title in the language in which the article was written.

38. Only the initials of the article title must be capitalized. The font of the article title must be Palatino Linotype, font size 14 and bold. 
39. The Name of the Author (bold, initials are capitalized), University, Department, Academic Title, e-mail, ORCID ID (italics, initials are capital) should be placed just below the title in the language in which the article is written. The font of the title must be Palatino Linotype, font size must be 11 .

40. Immediately after the abstract section, there must be an INTRODUCTION that specifies the purpose, scope, and methods of the article. Additionally, the article must be edited to include Result and Bibliography.

\section{Abstract}

41. It must be written separately in Turkish and English, not less than 100 words, not more than 300 words. The abstract must reflect the main idea of the article and its contribution to science. At the bottom of the abstract, there must be at least 3 and at most 5 keywords as in the template. The abstract's font must be Palatino Linotype, font size 10 and italic. The keywords must be written in bold capital letters. No citation must be made in the summary.

\section{Body Text}

42. The article must be written in A4 dimensions and the Word program must be used.

43. Line spacing is $1.15 \mathrm{~cm}$.

44. The font is Palatino Linotype, the font size is 11.

45. The paragraph spacing must be $8 p t$.

\section{Chapter Heading}

46. Main headings and subheadings can be used to determine the structure of the article and to ensure a regular information transfer in the main text.

47. After the INTRODUCTION is numbered 1 , the number must be assigned to other headings.

48. The font is Palatino Linotype, the font size is 12 .

49. Levels of Heading must be selects in styles in Word.

50. Main headings must be written in capital letters. Subheadings must be written in lowercase and bold, with the first letters capital. 


\section{Figure and Tables}

51. The figure number and description must be below the figure.

52. In the tables, the number and explanation must be above the table.

53. Paragraph spacing must be $0 p t$ in all directions, font size must be 10. Table height should be as narrow as possible depending on the content.

54. Table and figure descriptions' font size must be $\mathbf{1 0}$.

\section{Bibliography Style}

55. AJIT-e uses the latest version of APA as its bibliography.

56. Page, paragraph etc. information should be included in citation. Example: Incorrect: (Tingöy, 2009: 23) Correct: (Tingöy, 2009, s. 23)

57. Bibliography indent must be $\mathbf{1 . 2 5} \mathrm{cm}$ hanging and font size must be $\mathbf{1 0}$.

58. AJIT-e recommends using reference management systems such as Mendeley, Zotero, Endnote.

Authors who submit articles to AJIT-e are deemed to have accepted this policy. 


\section{AJIT-e Contact Information}

\section{Bilişim Teknolojileri Online Dergisi}

AJIT-e (Academic Journal of Information Technology)

Address: Kazım Ozalp Sk. No: 15 Kat 234740 Şaşkınbakkal / Suadiye / KADIKÖY /

ISTANBUL / TURKEY

Tel: +90216355 5619

Faks: +90 2163684330

Email: editor@ajit-e.org

\section{Supported by \\ ABA \\ Akademik Bilişim Araştırmaları Derneğ}

www.ajit-e.org $\quad$ www.abilar.org

AJIT-e has an Open Access policy and is licensed under the Creative Commons Attribution-

Same License Share 4.0 International License. Access to published articles is free. 